\title{
Computer Games versus Experiments
}

\author{
Uffe Thorsteinsson \\ Department of Industrial Management and Engineering, Technical University of Denmark
}

E-mail: uffet@ipv.dtu.dk

Key words: virtual games, games versus experiments

\begin{abstract}
Several questions are asked about the actual use of games. The need for development of realistic games is discussed, and some specific criteria for making games realistic are presented. Three examples are described. They are all based upon use of information technology and some new facilities offered by this technology. The three examples are hybrids between games and experiments, offering players important possibilities and freedom for $>$ design $=$ of the game or experiment they want to make. So, the examples all illustrate some new waves for games in industrial management.
\end{abstract}

\section{INTRODUCTION}

Computer games have been known for many years, but latest developments of information technology make it necessary to raise the questions:

- How will information technology change our possibilities for design of games?

- Has information technology already changed the design of games?

Several major changes are going on, possible and under way in Information technology field: We have a shift in using computers 
- From a means for computation of consequences and results in traditional games

- To an interactive tool in networks.

This opens possibilities for:

- Release of data and information during the game

- Communication between players - even geographically separated

- Group works on common files

- Players own handling of data and fast calculation - even with players' own models

- Visualization with video tapes or video conferences

and based on that we can create 'virtual' reality. However, the most important new issue is the hypertext. This allows going through a game via many different routes, depending on players' decisions.

So, which impact will these new possibilities have on our design and development of games in the future?

We have used information technology in education for many years, but the use has accelerated during the last 20 - 30 years.

\section{SOME CHARACTERISTICS FOR TRADITIONAL COMPUTER-BASED GAMES}

One characteristic is related to the functional task of the computer. Many computer-based games have a concept in which players have to make decisions and enter data in the computer. The computer makes a computation and answer with some consequences of the decision.

Another characteristic is related to the use of models in games: Normally models in the computers are unknown for the players. So, the game situation is an exercise in investigation of unknown models. Maybe this situation matches to a situation in the real world, but another educational situation could be: How to learn about the functionality and usefulness of different models? How can this situation be designed by use of Information technology? 


\section{Use of Information Technology in Education}

1. Word, language

2. Drawing, signs and letters

3. Books

4. Publishing
5. Photos and movies

6. Broadcasting

7. Overhead projector

8. Computers

9. Internet

10. Hypertext

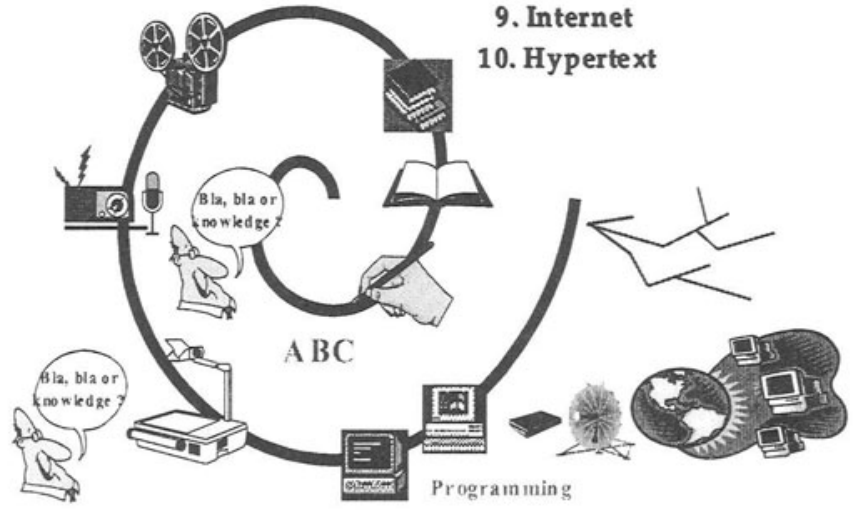

Uffe Thorsteinss on

Figure 1: During the latest years we have seen a rapid development of new technology that can be used in education.

\section{ARTIFICIAL - OR NOT?}

Games are artificial. Flowers can also be artificial. And lakes as well. However, there is a difference between the kind of 'artificial'. An artificial flower can never become real, but an artificial lake can - given time - be real! What about games?

Many games are far away from the real world.

- They are played in different surroundings

- Rules are artificial

- The accessories are in a special design for use in the specific game

- The problems in the games are not always realistic, because they are designed to illustrate how specific methods and tools can be used - so problems are often very simplified.

- Based on the above, people are therefore playing roles that do not really match their roles in real life. 
So, many games seem to be artificial. Another element can be added: What makes a game to a real game? Or: When is a game a game?

- Is a computer programme that has to be played by a single player a game?

- Is a computer programme, which can be used sequentially to calculate some consequences by two persons a game?

- Is a game in which all decisions must be made based on designers decision alternatives a game?

\section{EDUCATIONAL ACCESSORIES ...}

In a world in which multimedia are growing up everywhere, the potential players will expect more than a computer programme able to make calculations of some decisions. The traditional computer-based games with fixed models must be named educational accessories, and we need a new name for interactively used multimedia games.

A special sort of game is: Simulators, as they are used in different areas for training of operators. They should not be named games, but Simulators.

\section{WHAT MAKES COMPUTER GAMES REALISTIC?}

A development of realistic games - or a redesign of existing games - must include at least following elements:

- A realistic main topic in the game

This includes that the main scope for the game is based on problems from real world life in companies, and these problems (and the game set-up) are presented, as they would be in a running enterprise.

- The environment - the presented information

This can also be named as the wrapping. It is the system that gives the game a realistic view and functionality that matches the real world systems.

- The freedom for players to make decisions of their own

This freedom includes that the players have opportunities for making their own decisions, and not only to make preprogrammed decisions, designed by the game developer.

- The interaction between people

In the real world interaction exists between people. Therefore 'games' where a single player plays a computer-based game, are 
not games, because the interaction is not present. The computer is transformed to a simulator to train the person to press the right sequences of keys for having the best result. The interaction between people can be designed by different means - exactly as in the real world: Face-to-face, by talking via some technical devices, by written communication etc. The participants play roles, and they act not always rationally. So this interaction between participants must be included if a game should be realistic.

- The competition.

This element has two dimensions. First, in real world business competition is real, so a real business game must include this element by some integration of interaction from a market: Competitors, suppliers and customers. Second, the competitions can be a factor to motivate the players. The game must therefore be designed so at least two teams can go along simultaneously and by that create a situation with competition.

and

\section{- The trigger!}

This is the engine, which pushes the game forward. The clock cannot alone be the trigger - unless it is combined with releasing of some events. Such events can be based on receiving orders from customers. However, the realism in the game will strongly depend on types of events included. In an industrial enterprise stochastic events occur in many areas: In internal in organisation, in production systems, in the social system and in the surroundings to the enterprise: Markets, competitors, societies, life style trends, technological conditions, new products, information technology, political environments etc.

In the real world these events from various sources play an important role for how the 'real play' takes place! In a realistic game a trigger must be introduced, able to produce events that focus on the problems, the game is designed to illustrate.

\section{INFORMATION TECHNOLOGY'S OVERWHELMING IMPACT!}

One consequence of the very fast development of information technology has been, that focus has been moved away from other means in design of educational activities? A traditional means has been Experiments. 
In an attempt to structure different purposes and uses of game types as well, the model in fig. 2 has been published.

Simulation is used in different situations and must be designed according to the purpose. Following model describes games based on three dimensions:

- Game purposes from players point of view

- Game purposes from a system point of view

- Game categories - types of simulation

\section{SIMULATION GAMES - OR EXPERIMENTS?}

Over some years the author has been working with integration of information technology and use of the new possibilities in education in three different types of activities.

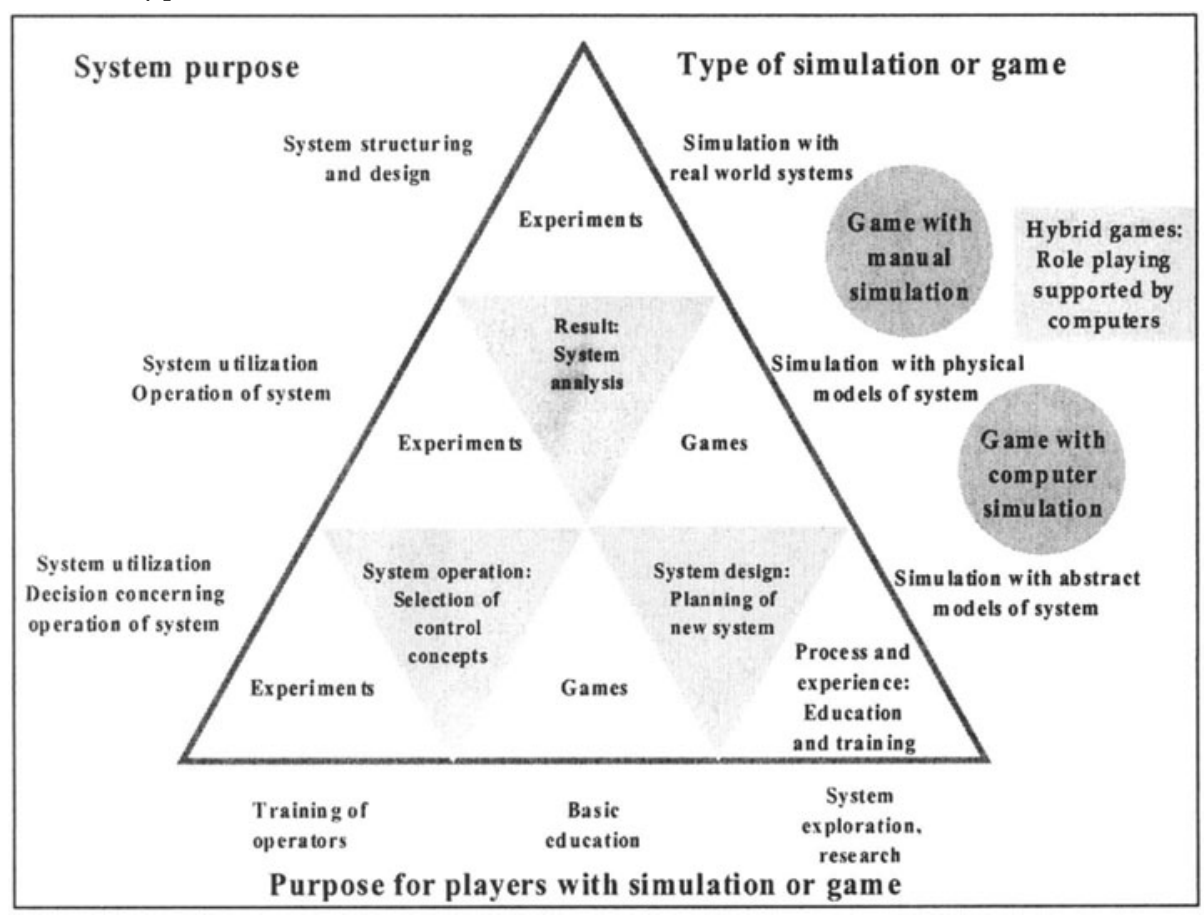

Figure 2: Simulation and experiments classified by three dimensions (ref 5). 


\section{LOGI GAME - A DISTRIBUTION GAME WITH OPEN MODELS AND STRUCTURE}

LOGI GAME is a logistic game with simulation of distribution in a simplified channel with three levels: One producer and two wholesalers, each with two retailers - in total seven enterprises. All these have to select material management and administrative models from a Modelbank with several pre built Excel models. Before the game starts, game manager and players can decide the demand structure in the market, overall organisation of the enterprises, game rules, etc. Therefore the players have possibilities for design of the Experiment. Models are known to the players, and players themselves design game rules. If they do not like the pre built Excel model, they are free to improve them - or to design their own ones.

The attempt to make a realistic game is handled by use of an event generator that stochastically creates events from market, production system and financial area. Since all enterprises need two players, many possibilities are open for role-playing and personal interaction. The game is designed so several types of experiments can be worked out. The game has earlier been described (ref 1, page 175 -184). Since then the game has been transformed so that it can be used on an Intranet with on-line information.

\section{A STUDENT PROJECT IN A PROJECT MANAGEMENT COURSE - AN EXPERIMENT}

A main problem in teaching project management to students is their lack of work experiences in an organisation. Therefore it might be difficult for them to understand both the importance as well as the content in 'soft topics' such as conflict solving, commitment to plans and budget.

Based on this, in a first phase a course in project management was changed, so it partly ran as a project, where the students themselves should 'run the course'. This includes making several different 'deliverables'. The participants had to plan and carry out several activities and produce deliverables within the course main topics. During the project the participants have to work with several methods and tools - and not only read about them. The teacher has decided the general frame for the course - and deviating from this was not possible. The frame ensures that important topics are included in the course.

After three years with this experiment the course was changed in a second phase, so it also integrates Information technology in the communication and interaction among all members in project organisation. 
Since the course runs with 70 - 80 students, with exercise on different workdays, there is intensive communication.

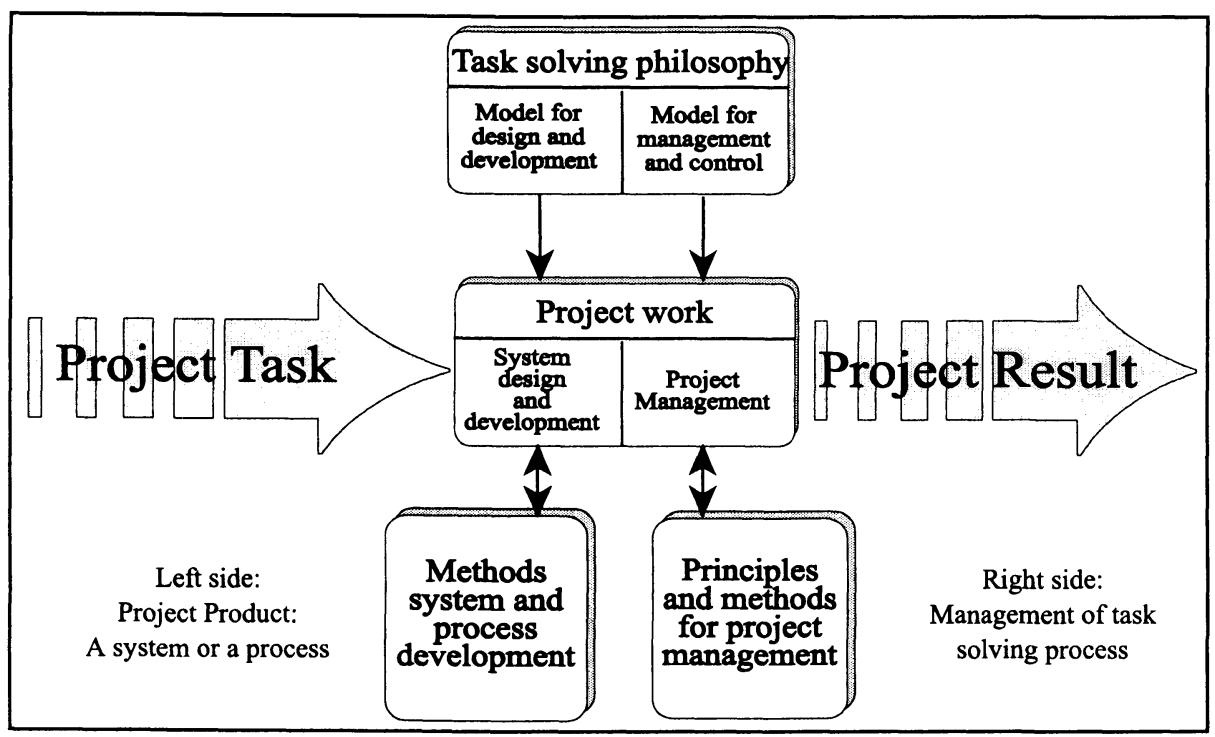

Figure 3. The experiment concerns a unique project where the left part concerns a process oriented project about project management it self: Running a course in project management. Production planning is here related to a specific area.

So, the course was really a great simulation - or experiment - with running a project. Of course, it had some very specific characteristics. Figure 3 shows that projects consist of two parts: The managerial part and the 'project product development part'. The last part concerns development of a system or in other cases of going through a process - as for example organisational changes or educational programmes. All projects do have specific characteristics, and the characteristic ones for this course were, that the content in the left part was the project management course it self. So the students had on one hand to develop the course content themselves, and on the other hand to manage the project: A project organisation with app. 80 part time members working on 5 different week days. One thing was sure: When so many students have to work together and produce deliverables to a project, they will also create many problems and conflicts. An important thing is that teacher or designer does not pre-program the sequences of problems and conflicts. They are a result of interaction between students and the decisions they made. So the learning effect from the experiments was based on as well their group work with several different deliverables as upon 
their experiences with, how problems and conflicts start, runs and maybe also can be solved.

In figure 4 is shown the start page of the course WEB site. In the students' section there is a system for systematically recording problems and experiences.

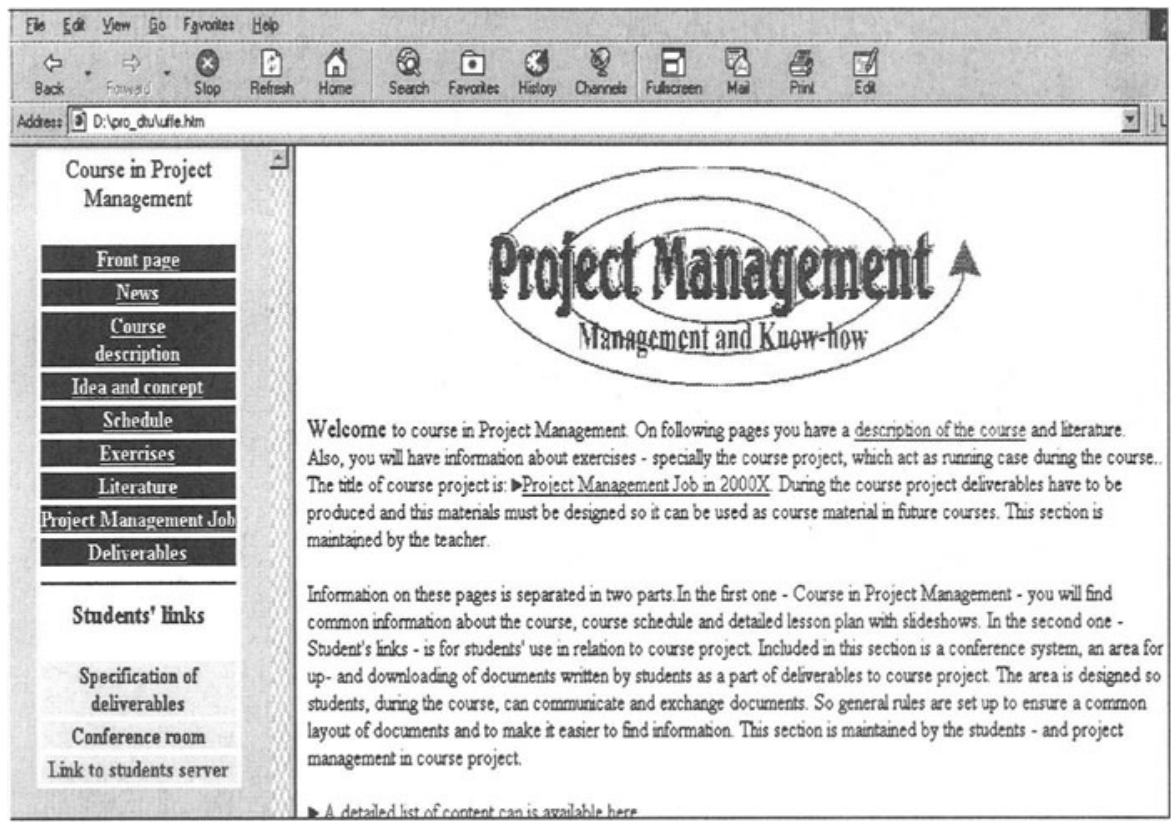

Figure 4. Use of information technology was based on a web site with two sections. One for all teacher's course material and one for the student communication: File sharing, discussion groups and a very special thing: A logbook section for recording of student experiences during the project.

Further there is a link to an Internet-based project management game: Based on detailed logbooks from previous years, an on-line Internet decision-based game has been developed. This game is now used to prepare the student to some of the typical problems and conflicts, the project management is facing in the student project.

\section{A VIRTUAL COMPANY ON INTERNET - A FRAME FOR SEVERAL GAMES}

Based on the concept from the LogiGame the idea was born to develop a general virtual company, which could be used as general basis for several 
different types of business games. The idea was, that the company should be presented on Internet as 'a real company'. This idea has been described in more details in other papers (Ref. 3 and 4).

The virtual company: SnapHane produce beer brewing automates, a new product to be introduced on the market. Therefore the enterprise has to be established with an organisation, production system, information system etc. Some of the basic ideas are that:

- the work should be done by students' work at different universities and engineering schools - based on a general concept.

- a Modelbank should be established with descriptions and Excel models of several methods and procedures from the industrial engineering fields

- the virtual company and Modelbank should be available for different types of educational activities:

- Specific analysis of different topics and development of possible solutions

- Running the company via different sorts of games - and by that bringing the company in an operational phase

- Development projects related to company systems and products, such as the SnapHane educational system itself (for example development of new games)

- Development of models and material for the Modelbank.

Figure 5 illustrates how the SnapHane has two parts: A management part and an operational part. Figure 6 illustrates how it could be possible to integrate different existing games into a common structure based on data and information from a common enterprise.

At the moment different students works are going on with development, and some thesis work have been finished. A new model of beer brewing automate has been developed with full documentation of the product itself and the development project (ref. 6). Based on this a Internet based product development game has been developed in another thesis work (ref. 7). Other students are working with development of different models to the Modelbank. 


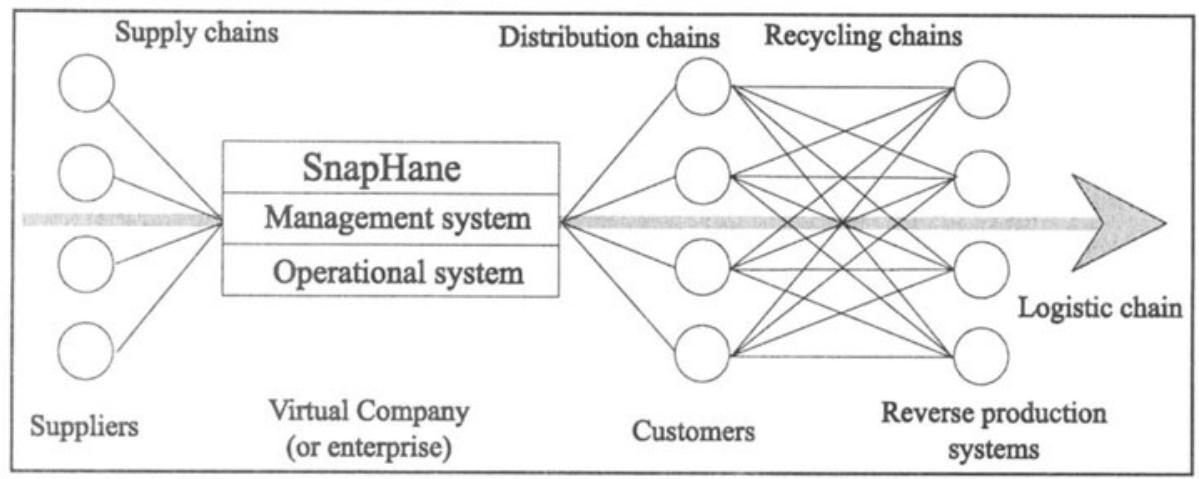

Figure 5. The SnapHane company can be developed in different directions. First part is the organisation, products, production and information systems.

Seconds part is supply and distributions channels.

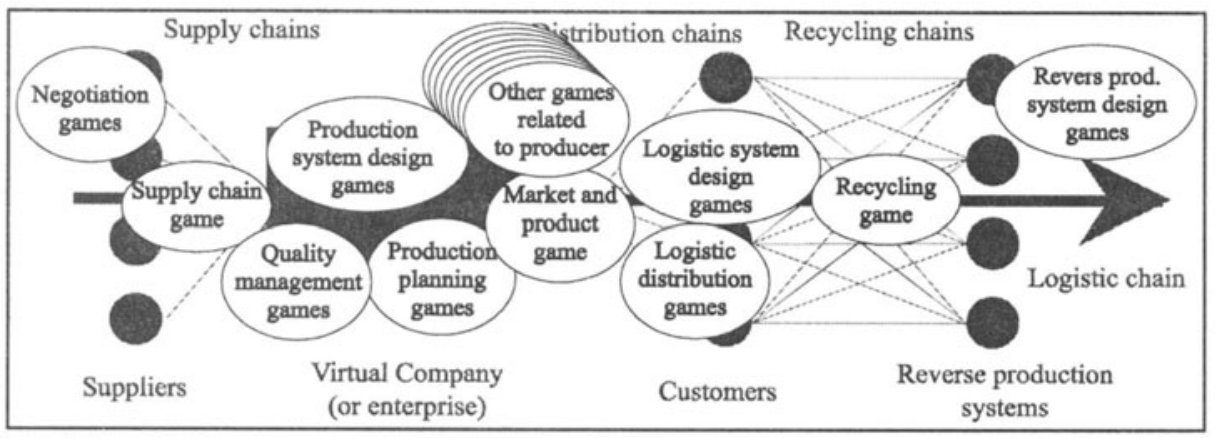

Figure 6. If possible other games from various sources can be transformed so the result could be a comprehensive collection of different business games, all related to a common enterprise.

So the idea is, that the SnapHane company will grow - and grow with a speed depending of the number of students, who want to work with development of this company. The value of the system will increase, if students from different countries and universities contribute to the development, supported by teachers from institutes. On longer terms it might be possible to play games with this virtual company via Internet with players from different universities. The virtual company could be split up with departments located at different universities or with customers or supplier in different countries.

The information technology opens new possibilities for design of business games and games in production management. 


\section{REFERENCES:}

Thorsteinsson, Uffe (1995) The Logi Game. A Dynamic Modular Logistic Game. Paper in Simulation Games and Learning in Production Management. Edited by Jens O. Riis. Chapmann \& Hall. London. ISBN 0412721007.

Thorsteinsson, Uffe (1998) Changing Pedagocigal Means in Project Management Education. Paper i proceedings from $14^{\text {th }}$ World Congress on Project Management, Ljubljana, Slovenia, page $652-660$.

Riis, Jens O, Uffe Thorsteinsson, Ari Barfod and Erik Lyngsie (1997) The Role of Games in a Model Company. Paper in proceedings of the Third Workshop on Games in Production Management, Espoo, 27 -29 June, Finland, page 67- 72.

Thorsteinsson, Uffe (1997) A Virtual Company for Educational Purpose. Proceedings of the Thirty-second International Matador Conference. Manchester. $10-11$ July 1997. Ed. by A. K. Kochhar. Page $221-226$.

Thorsteinsson, Uffe (1997) Model presented in 1997 in a slide show on SnapHane Web pages.

Polo del Valle, Antonio and Manuel Munarriz Cardiel (1998) Conceptual Design of a Home Brewing Machine. Thesis work at Department of Industrial Management and Engineering, Technical University of Denmark. 1998.

Rodríguez Vicente, Marta P. and F. Ivan Sáenz Gil de Gómez (1999) ProDeNet. The New Game that Simulate a Project of Project Development on Internet. Thesis work at Department of Industrial Management and Engineering, Technical University of Denmark. 1999.

\section{BIOGRAPHY}

\section{Uffe Thorsteinsson}

Uffe Thorsteinsson is associate professor at Department of Manufacturing Engineering, Production Management at Technical University of Denmark. He has been working several years in the fields of project management, logistic, plant facilities and maintenance. Experiences from consulting work, teaching at university, business school and courses for professionals from different fields. He has been president for $\mathrm{He}$ has been president of Europäische Hochschullehrer Gruppe, Technische Betriebsführung (EHTB) 1997 - 1999. 